\title{
User Information Needs for Environmental Opinion-forming and Decision-making in Link-enriched Video
}

\author{
Ana Carina Palumbo \\ University of Amsterdam \\ Science Park 904, 1098 XH Amsterdam, NL \\ a.c.palumbo@tue.nl
}

\begin{abstract}
Link-enriched video can support users in informative processes of environmental opinion-forming and decision-making. To enable this, we need to specify the information that should be captured in an annotation schema for describing the video. We conducted expert interviews to elicit users' potential information needs. We carried out a user survey to assess the relevance of the identified information types. Finally, we observed users' behaviour and needs when presented with a selection of video segments. Our results indicate that certain types of information about the environmental problem, the opinions expressed, the people expressing them and the sources are more relevant for users.
\end{abstract}

\section{Categories and Subject Descriptors}

H.5.4 [Hypertext/Hypermedia]: User issues

\section{Keywords}

User information needs, link-enriched video, opinion-making, decision-making, interactive TV, environmental issues

\section{INTRODUCTION}

The deterioration of the ecosystems on which we depend is currently one of the most important international concerns we face. The participation of informed citizens in the debate on decisions affecting sustainable development of our society is fundamental to addressing these issues [2]. Television plays a key role in providing audiovisual information, which enables the communication of extensive amounts of information quickly. It also enables conveying feelings, emotions and abstract interactions, which are difficult to express through other media [5]. By combining the potential of audiovisual

\footnotetext{
* currently affiliated with Eindhoven University of Technology, Eindhoven, NL

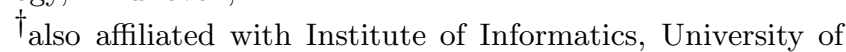
Amsterdam, NL
}

Permission to make digital or hard copies of all or part of this work for personal or classroom use is granted without fee provided that copies are not made or distributed for profit or commercial advantage and that copies bear this notice and the full citation on the first page. To copy otherwise, to republish, to post on servers or to redistribute to lists, requires prior specific permission and/or a fee.

EuroITV'13, June 24-26, 2013, Como, Italy.

Copyright 2013 ACM 978-1-4503-1951-5/13/06 ...\$15.00.

\author{
Lynda Hardman \\ Centrum Wiskunde \& Informatica (CWI) \\ Science Park 123, 1098 XG Amsterdam, NL \\ Lynda.Hardman@cwi.nl
}

information to engage and entertain with the capacity of digital hypermedia to connect ideas, link-enriched video can enhance the processes of opinion-forming and decision-making, e.g. in the context of environmental issues.

Our challenge is to identify the information that should be captured in video annotations that will support the enrichment of TV broadcasts with information that is pertinent to users. The main problem is the gap between what users' need and what broadcasters can do to meet these needs within their time and budget constraints. In this paper, we specify the information that should be captured in an annotation schema for link-enriched video that is able to support users' information requirements in the processes of opinion-forming and decision-making on environmental issues. Specifically, we identify information that can be provided and prioritise users' information requirements.

We conducted expert interviews (section 3 ) to consolidate an inventory of types of information that users need to form opinions and make decisions on these issues. From these we selected specific user requirements by conducting: a user survey (section 4) to gain insights into the information and tools that users claim they need; and a user experiment (section 5), to directly observe the types of information that participants used.

\section{RELATED WORK}

Environmental issues are notoriously complex, and require the understanding of different types of information from many perspectives [6, 7]. Opinion-forming and decisionmaking require "a complex search for information, full of detours, enriched by feedback from casting about in all directions, gathering and discarding information, fueled by fluctuating uncertainty, indistinct and conflicting concepts" [7](p.86). Link-enriched video has the potential for rapid information location within collections of video material by allowing users to select content segments, jump to related information during playback, and return to material earlier in the sequence or a previous segment [3].

Through a literature review, we identified and selected a number of information types that describe aspects of environmental videos. These provide an initial framework for the study of information requirements in this domain. The types and their references can be seen in Table 1 .

We use this groundwork on information to form opinions to guide the series of interviews with experts on the topic.

When environmental problems are under debate, people express their opinions. Therefore, considering argumentation and rhetoric in the annotation of videos in this domain 
Table 1: Information that could be captured in an annotation schema. The items were selected from literature (L) and/or interviews (I).

\begin{tabular}{|c|c|}
\hline Types of information & Sources \\
\hline \multicolumn{2}{|l|}{ Details of the environmental problem } \\
\hline $\begin{array}{l}\text { Basic description: Type-Subject-Location } \\
\text { - Date - Physical, chemical and biological } \\
\text { processes. }\end{array}$ & $\mathrm{L}[4]$ and $\mathrm{I} 4$ \\
\hline $\begin{array}{l}\text { Impact: scale (individual, local, regional, } \\
\text { national, global) - Affect on human commu- } \\
\text { nities, health and species }\end{array}$ & $\begin{array}{l}\mathrm{L}[4], \mathrm{I} 2, \mathrm{I} 4 \\
\text { and } \mathrm{I} 5\end{array}$ \\
\hline $\begin{array}{l}\text { Temporality: Background of the issue } \\
\text { (lessons learned, causes) - Outcomes (short- } \\
\text { term) - Future scenarios (long-term) }\end{array}$ & $\begin{array}{l}\mathrm{L}[4], \mathrm{I} 1, \mathrm{I} 2, \\
\mathrm{I} 4 \text { and } \mathrm{I} 5\end{array}$ \\
\hline $\begin{array}{l}\text { Personal implications: Responsibilities - In- } \\
\text { struments to take action }\end{array}$ & $\mathrm{I} 4$ \\
\hline $\begin{array}{l}\text { People involved: Types of actors - Objec- } \\
\text { tives }\end{array}$ & $\mathrm{L}[4]$ and I5 \\
\hline \multicolumn{2}{|l|}{ Position/Opinion } \\
\hline $\begin{array}{l}\text { Argument: Direction (favorable, unfavor- } \\
\text { able, neutral) - Degree - Saliency - Rethorics } \\
\text { (Ethos,pathos/intensity, logos) - Temporal- } \\
\text { ity - Advantages - Relation to other argu- } \\
\text { ments (opposite, similar) - Dimensions (Sci- } \\
\text { entific, social, cultural, economic, political, } \\
\text { ethical, technical, legal, safety and security, } \\
\text { historical) }\end{array}$ & $\begin{array}{l}\mathrm{L}[4], \mathrm{I} 1, \mathrm{I} 2, \\
\mathrm{I} 3, \mathrm{I} 4 \text { and } \mathrm{I} 5\end{array}$ \\
\hline $\begin{array}{l}\text { Public opinion: Stage of attention cycle } \\
\text { (saliency) - Distribution - Saliency - Extent } \\
\text { of consensus }\end{array}$ & $\mathrm{L}[4]$ \\
\hline \multicolumn{2}{|l|}{ Person } \\
\hline $\begin{array}{l}\text { Type of actor - Details (age, name, culture, } \\
\text { values, profession and occupation, location, } \\
\text { educational background, biography, related } \\
\text { organisations and affiliations) - Arguments } \\
\text { expressed - Personal benefits }\end{array}$ & $\begin{array}{l}\mathrm{L}[4], \mathrm{I} 1, \mathrm{I} 3 \\
\text { and } \mathrm{I} 4\end{array}$ \\
\hline \multicolumn{2}{|l|}{ Sources } \\
\hline $\begin{array}{l}\text { Name - Level of trustworthiness } \\
\text { Type (Wikipedia - Books, - Magazines - Sci- } \\
\text { entific papers and reports - Newspapers - } \\
\text { Documentaries - Videos - TV programs - } \\
\text { Websites - Social sites - Radio broadcasts) }\end{array}$ & $\mathrm{I} 2, \mathrm{I} 3$ and $\mathrm{I} 5$ \\
\hline
\end{tabular}

is fundamental. We base the information types related to points of views and positions on the model proposed by Bocconi et al.[1].

\section{EXPERT INTERVIEWS}

Expert interviews were conducted to inventorise the spectrum of types of information users need.

\subsection{Method}

Interviewees. Five experts were interviewed: a project manager who works for a broadcaster (interviewee 1, I1); a social communicator who works with environmental risks and disasters in a governmental organization (I2); a researcher and developer of videos and documentaries in a research institute (I3); a project manager who designs environmental education programs in a non-governmental organisation (I4); and an expert who works for environmental and water consultancy in a governmental organisation (I5).
Interview. Two types of semistructured interviews were conducted: one for experts from the field of video production and broadcasting (I1, I3) and another for environmental governance experts (I2, I4, I5). The specific questions asked can be found in [4].

\subsection{Results and discussion}

According to the experts, users require sufficient information to form a complete, unbiased and informed opinion or decision (I4 and I5). The types of information that experts mentioned are summarized in Table 1.

Both literature and experts indicate that environmental video content can be enriched from multiple perspectives. All information previously elicited was organized in types and subtypes to configure a set of data to be used in the next stages of the study (Table 1). Annotating all these types of information in video content might not be viable and feasible for broadcasters. A prioritisation is needed and thus we ask potential users.

\section{USER SURVEY}

We conducted a user survey to assess the types of information that could be captured in an annotation schema. Users were asked to reflect on their information needs when forming their environmental opinions or decisions.

\subsection{Method}

Survey. An online survey of 19 questions was carried out from May 26th to June 3rd 2012. It included general questions and specific ones on shale gas drilling. Users had to imagine that there was a project aiming to build a shale gas drilling pad in their own region. They were asked to suppose they were informing themselves on the topic. Two video segments were shown (see questions in [4]).

Measurements. The types of information in Table 1 were included in the survey. For most of the questions Likert scales of 5 items were used. In other cases, users were asked to rank variables using a drag and drop function (options were randomly ordered to reduce bias). Text fields for comments and open questions were included.

Participants. The sample comprised 213 participants. Respondents varied in age, gender, country of residence, level of education and frequency of time spent watching TV, online videos and reading the newspaper.

\subsection{Results and discussion}

The main results of the survey are shown in Figure 1.

Whereas around $90 \%$ of the respondents agreed that identifying whether a statement is a fact or an opinion is important $(\mathrm{M}=4.3, \mathrm{SD}=0.7)$, only $73 \%$ stated that it is possible to differentiate them in a discourse $(\mathrm{M}=3.8, \mathrm{SD}=0.8)$.

Even though users claimed that factual information is more relevant than emotional and ethical arguments, when being asked about the usefulness of two video segments they had seen (one classified by them as an opinion and the other as a blend of facts and opinions) no difference was made. There is a contradiction between what they claimed that is relevant and the level of usefulness assigned to the video segments they watched.

The 3 most useful sources of information for users are: scientific papers and reports $(\mathrm{M}=9.5, \mathrm{SD}=2.6)$, documentaries $(\mathrm{M}=8.4, \mathrm{SD}=2.4)$; and newspapers $(\mathrm{M}=6.6$, $\mathrm{SD}=3.2)$. 
(a) User interest in types of arguments

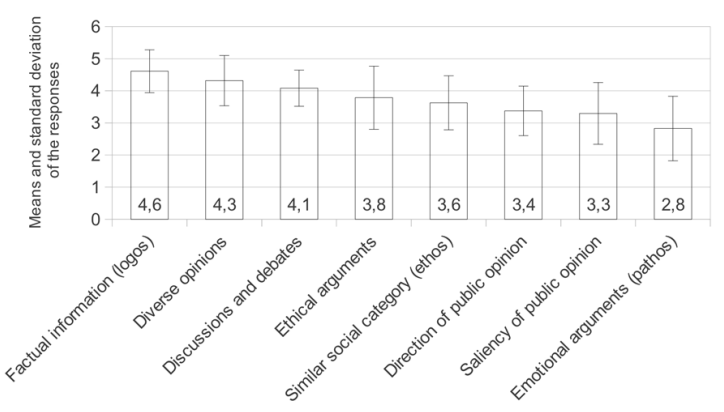

(b) Relevance of details of the problem

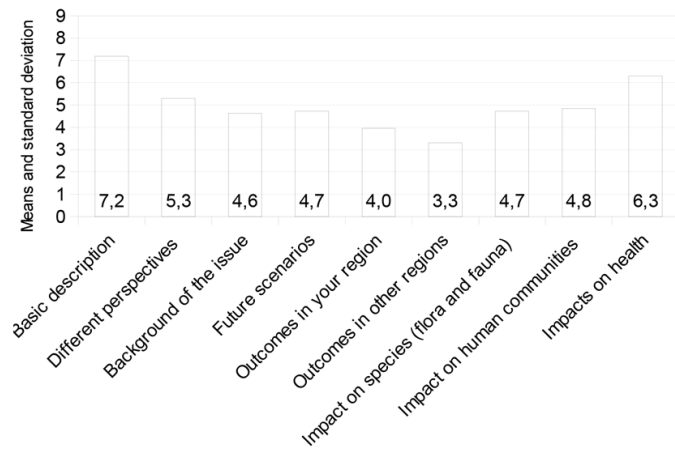

(c) Relevance of information to be captured when annotating people

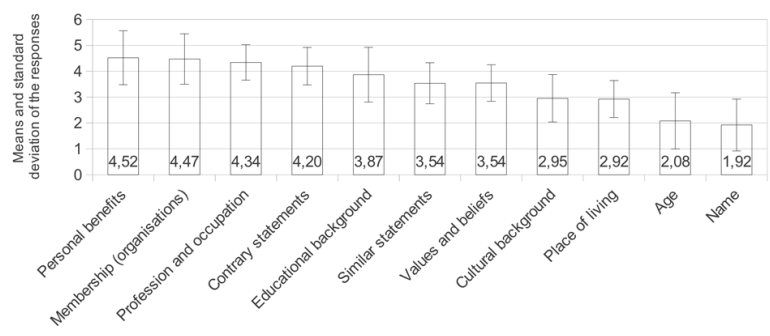

(d) Relevance of the dimensions of analysis

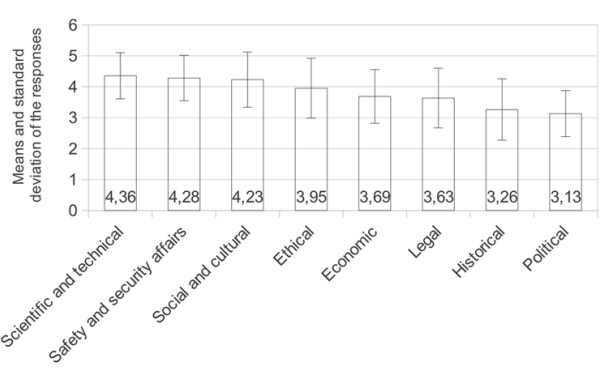

(e) Relevance of types of actors

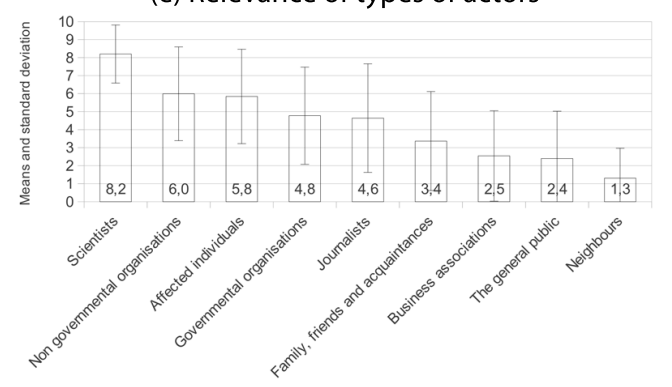

Figure 1: User survey results.
The most frequent need expressed was to have access to evidence, facts, objective and unbiased information, exact data and results from research. Opinions from "independent" people (not affiliated or part of a company) holding a "neutral" and "honest" position were highlighted.

Users prefer complete information over pieces of information. They want benefits and disadvantages, pros and cons of the issue and costs and benefits. Risks involved and other aspects related to the safety, security and health implications, and the consequences in the short and long term were mentioned by many participants. Some users find the scientific and technical perspective more relevant than the security and safety perspective, whereas in open questions users' expressed their interest for the latter.

A frequent information need is to know about possible alternatives to achieve the same goals. Users want to compare benefits and disadvantages of these to choose the best cost-benefit balance. They are also interested in knowing about the level of community need for the benefits of the issue under discussion. Several participants mentioned the need to know who benefits, who is making money out of it, who support the initiatives and who are against.

\section{USER EXPERIMENT}

To assess the level of priority of the types of information needed for forming opinions and making decisions, we observed the way users perform information tasks on a specific environmental issue. We compared the results with those obtained in the user survey.

\subsection{Method}

We created a website including meaningful titles for 25 segments on shale gas drilling depicting a single speaker's or organisation's opinion. Each represented a type of information from our initial set (Table 1). 6 participants, of which 5 female, had to select a video segment using its title, from which we inferred the type of information they wanted.

Procedure. Users watched a short video introducing the issue and were then asked to imagine that they had to decide whether to sign a petition for or against shale gas extraction in their region. To inform themselves, they chose 3 video segments. Before and after watching each segment they were asked about their expectations and the reasons for their choice. After each segment, they were given 3 minutes to consult online resources. They had to decide whether they agreed with or believed the ideas expressed; or they had to check any other additional information need triggered by the segment. Finally, users were asked to rank and explain the usefulness of the sources they used.

\subsection{Results and discussion}

Three participants (P1, P5 and P6) decided to watch the "Arguments supporting shale gas drilling". Other segments were chosen by two participants: "Impact on human communities" (P1, P3), "Arguments against shale gas drilling" (P4, P5), "Potential outcomes" (P4, P6), "Diverse opinions" (P2, P6), "Health implications" (P3, P5). Users chose to access the video segments using a dimension of analysis in 4 cases, the direction of the opinion in 5 cases and using other categories in 9 cases. None of the participants chose a segment titled by the type of actor giving arguments. A detailed analysis of the results can be found in [4]. The most 
frequently expressed needs were safety, security and health implications, outcomes and future scenarios.

Words and phrases such as "impacts", "effects", "risks" "disadvantages" and "health implications" were used in users' queries. When searching for information online after watching each segment, some participants found difficulties in specifying terms for their queries. One participant expressed her/his desire to access an explanation in "easy words". 3 participants were interested in checking alternatives to shale gas drilling or solutions implying less negative impacts for human beings (P2, P3, P6).

The need to consider opinions from people that are more neutral, objective or that do not have particular interests or benefits on the issue was highlighted.

Even though most of the participants stated their intention to be informed from many points of view, they tended to choose all the segments following one topic or direction. 5 participants decided to be against shale gas drilling almost from the beginning of the experiment ( $\mathrm{P} 4$ was the exception). When a segment contained supporting arguments they considered them as less useful and biased. This confirms what persuasion theories state: users tend to give more weight to arguments that support their own opinion.

Two participants (P3 and P4) had chosen 3 segments in advance and later decided to switch them. This could indicate that information needs evolve while forming an opinion and are renewed each time new information is processed.

All participants used the Google search engine, 3 accessed Wikipedia, 2 scanned Google results lists, 1 accessed Google Scholar (P2), 1 used YouTube (P5). Other sources used were news sites and web sites specialized in the topic.

The use of Wikipedia in the experiment suggests its relevance, even though in the survey it was ranked in the 6 th position out of 9 . Users did not always pay attention to the name of the source or its credibility. Many of the sources they opened were not familiar to them. Only one participant reflected on the importance of the trustworthiness of the source (P2). Participant 3 considered whether the site contents were reviewed by experts or not to rank them. In many cases users scanned scientific papers and reports.

Even though on several occasions participants mentioned they wanted to listen to an expert, none chose to access a segment representing the opinion of a particular actor. To determine whether to believe a speaker or not, users searched for concepts mentioned by the speaker. A participant (P4) expressed s/he wanted to know the name of the speaker to look for information about his background.

\section{CONCLUSION}

From the broad spectrum of information that could be captured in video annotation we identified the most meaningful types for users:

- Details about the problem: location and date; advantages and disadvantages of the main environmental processes involved, the level of community need for the resulting benefits, possible alternatives and outcomes for the community.

- Position or opinion: direction of arguments, relations between the main topic and other topics and arguments about the future; safety, security and health implications; scientific and technical perspective; level of subjectivity (pathos) and objectivity (logos) identified in a discourse; direction of opinions (favourable, neutral or unfavourable) and relation between them (opposite or similar).

- Person: how the speakers benefit from the position they hold, the organisations and affiliations s/he belongs to, his/her name, profession and occupation; links to different arguments expressed by a speaker and relation between those arguments (opposite or similar); experts' and scientists' explanations.

- Sources: the name and level of trustworthiness is relevant; users prefer scientific papers and reports and Wikipedia to enrich the video content.

\section{ACKNOWLEDGMENTS}

This work was partially supported by LinkedTV, funded by the European Commission through the 7th Framework Programme (FP7-287911). We would like to thank: Frank Nack, University of Amsterdam, NL; Daphne Willems, Daphnia: vision on rivers, NL; Lotte Belice Baltussen, Research \& Development Department, Netherlands Institute for Sound and Vision, NL; Nicolas de Abreu Pereira, Rundfunk BerlinBrandenburg, Germany; Santiago Gaitan, Delft University of Technology, NL; Veronica Viduzzi, Emmanuelle BeauxisAussalet, Mieke Leyssen and Stefano Bocconi.

\section{REFERENCES}

[1] S. Bocconi, F.-M. Nack, and L. Hardman. Automatic Generation Of Matter-Of-Opinion Video Documentaries. Journal of Web Semantics, 6(2):139150, April 2008.

[2] R. Declaration. Rio declaration on environment and development. In Report of the United Nations conference on environment and development, Rio de Janeiro, pages 3 - 14, 1992.

[3] A. Girgensohn, L. Wilcox, F. Shipman, and S. Bly. Designing affordances for the navigation of detail-on-demand hypervideo. In Proceedings of the working conference on advanced visual interfaces, pages $290-297,2004$.

[4] A. C. Palumbo and L. Hardman. Investigation Towards Link-Enriched Video: User Information Needs For Environmental Opinion-Forming And Decision-Making. CWI Technical Report INS-1301, URI: http://persistent-identifier.org/?identifier =urn: nbn:nl:ui:18-21150, CWI, January 2013.

[5] F. Shipman, A. Girgensohn, and L. Wilcox. Authoring, viewing, and generating hypervideo: An overview of hyper-hitchcock. ACM Trans. Multimedia Comput. Commun. Appl., 5(2):1 - 19, Nov. 2008.

[6] C. L. Spash. Informing and forming preferences in environmental valuation: Coral reef biodiversity. Economic Psychology, 23(5):665-687, Oct. 2002.

[7] M. Zeleny. Multiple criteria decision making, volume 25. McGraw-Hill New York, 1982. 